\title{
소통하는 공적개발원조
}

- ODA 백서 발간 -

전 규 석 (국무조정실 개발협력정책관실 대외협력과장)

\section{목 차}

I. 서론

II . 본론 : 공적개발원조(ODA) 백서 발간

$\mathbb{I}-1$ 백서 수립 배경

II-2 주요 선진 공여국 사례

II-3 백서 수립 체계

II -4 백서 구성 및 내용

III. 결론

\section{I . 서론}

한국은 단기간내 민주화로의 이행과 함께 경제사회 발전을 이룩함으로써 국제사회에서 수 원국에서 공여국으로 발전한 모범사례국이며, 새천년개발목표(Millennium Development Goals, MDGs) 달성을 위한 국제사회의 논의에 대해 인식을 공유하고 이러한 연대에 적극적으 로 동참해 오고 있다. 
이러한 우리 정부의 노력은 개발도상국에 대한 공적개발원조(Official Development Assistance, ODA) 지원의 양적 확대 및 질적 개선으로 나타나고 있으며, 공여국과 수원국 공 동의 정책적 노력에 동참하는 형태로 이루어지고 있다.

한국은 대내적으로 국제개발협력 기본법령 제정, 선진화 방안 마련 등을 통해 ODA 관련 법 적·제도적 틀을 구축하는 한편, OECD 개발원조위원회(Development Assistance Committee, $\mathrm{DAC}$ )에 가입함으로써 책임있는 국제사회의 일원으로서 국제사회 $\mathrm{ODA}$ 논의에 모범적으로 기 여해 오고 있다.

우리 정부는 향후 5 년간 추진해야할 140 개 국정과제를 선정하여 이행 중에 있으며, 그 중『 $\mathrm{ODA}$ 지속 확대 및 모범적·통합적 개발협력 추진』과제 이행을 위해 ODA 이해 주체들과의 협 업 노력이 전개 중이다.

특히, 어려운 국내·외 재정 여건하에서 ODA 규모를 확대하기 위한 노력을 지속해 오고 있으 며, 이를 위해 ODA에 대한 국민적 공감대를 확대해 나가고 있다. 아울러, 국제사회의 빈곤퇴 치와 지속가능발전을 위한 한국의 역할 및 한국 $\mathrm{ODA}$ 의 목표와 비전을 국민들과 국제사회와 공유해 나가야 할 필요성이 점진적으로 높아지고 있다.

따라서, 국제개발협력분야에서 그간 한국의 역할과 노력에 대해 다시 한번 고찰하고, 새로 운 지평을 향해 나아가기 위한 한국 $\mathrm{ODA}$ 의 방향에 대한 국민들의 이해도를 제고하여 지속적 인 원조확대를 위한 국민적 지지 기반을 마련하는 것이 그 어느 때보다 필요한 시점이라 할 것 이다.

\section{II . 본론 : ODA 백서 발간}

\section{II-1. 백서 수립 배경}

$\mathrm{ODA}$ 백서 발간 논의의 출발은 그간 정부 및 시민사회, 학계 등 민간부문에서의 수요를 반 영한 것이다. 
한국은 2010년 OECD DAC에 가입하고, 국제개발협력 기본법 마련 등을 통해 관련 법령 구 축 등 국내 원조체계를 제도화하고, 원조 규모의 양적 증대 및 질적 개선을 위해 노력중인 바, 이러한 정부의 노력을 대내외에 알릴 필요성이 있다.

금년 2월 개최된 제 15 차 국제개발협력위원회에서도 “소통하는 ODA" 추진을 위한 대한민국 ODA 백서 발간의 필요성이 제기되었고, ODA 백서를 2013년 말까지 발간하도록 의결한 바 있 다. 아울러, 신정부의 국정과제 중 하나인 “ODA 지속 확대 및 모범적·통합적 개발협력 추진”의 하위 과제로서, 민관 소통을 위한 ODA 백서를 발간토록 하였다.

ODA에 대한 국민들의 이해도를 높이고 정책기반에 대한 지지를 확보하기 위해서는 대국민 $\mathrm{ODA}$ 인지 제고를 위한 소통의 필요성이 대두된다. 이러한 맥락에서 우리 정부의 국제개발 협력에 대한 이해를 증진하는 사업으로 ODA 백서 발간은 그 의미가 크다.

특히, 금년은 2010년 발표된 ODA 선진화 방안에 대한 중간 점검기회이자 2016년 마련될 5 개년 $\mathrm{ODA}$ 기본계획의 수립을 위한 중간 시기이므로 한국의 ODA 백서 발간을 위한 시의적절 하고 의미있는 해이기도 하다.

이러한 ODA 백서 발간은 한국 ODA 정책 및 전략, 원조 성과 및 향후 나아가야 할 방향 등 에 대해 $\mathrm{ODA}$ 관계자 및 일반 국민들과 공유함으로써, 우리 ODA에 대한 국민들의 이해와 관 심을 고취해 나갈 수 있을 것으로 기대한다.

\section{II -2. 주요 선진공여국 사례1)}

정부의 문서들은 다양한 형태로 구체화된다. 이러한 정부 문서들은 '청서(Blue book)', '녹 서(Green book)' 및 '백서(White book)'와 같은 다양한 형태로 공개된다.

'청서(blue book)'는 주로 내각책임제 국가에서 사용되는 의회 보고서를 칭하며, '녹서 (Green book)'는 정부정책 및 전략에 대한 연구보고서를 지칭한다. '백서(White book)'는 정 부 공식문서로 정부정책에 대한 국민/이해당사자들이 이슈를 이해하고 문제를 해결하고 결정 을 내릴 수 있도록 돕는 역할을 위해서 마련된다.

1) 동 목차의 주요 내용은 이화여자대학교, 2013, ODA 백서수립 및 시행체계 사례연구, 중간보고서 내용을 인용하였다. 
OECD DAC 회원국들도 관련 자국의 ODA 정책, 법률, 학술연구 등 개발협력 관련 ODA 백 서 및 정책서를 수립하고 이를 활용하고 있다.

OECD DAC 회원국 가운데, 노르웨이, 독일, 미국, 아일랜드, 영국, 일본, 캐나다, 호주 등 8개국이 ODA 백서를 수립하고 발간해 오고 있다.

이와 함께, 네덜란드, 뉴질랜드, 덴마크, 룩셈부르크, 스웨덴, 스위스, 오스트리아, 프랑스 및 핀란드 등 9 개국은 별도의 백서를 발간하지 않고, ODA 정책서를 통해 자국의 ODA 정책목 표와 전략을 명시하고 있다.

마지막으로 그리스, 스페인, 이탈리아, 포르투갈, 벨기에 등 5 개국은 보다 간략한 액션 플랜 또는 마스터 플랜을 수립하여 활용하고 있다.

\section{〈표 1〉 OECD DAC 회원국의 ODA 정책 및 백서 수립 현황}

\begin{tabular}{|c|c|c|}
\hline $\begin{array}{l}\text { ODA 백서 발간 } \\
\text { 수립 국가(8개국) }\end{array}$ & $\begin{array}{l}\text { ODA 정책서 수립국가 } \\
\text { (백서 미수립) (9개국) }\end{array}$ & 기타(5개국) \\
\hline $\begin{array}{c}\text { 노르웨이, 독일, 미국, } \\
\text { 아일랜드, 영국, 일본, } \\
\text { 캐나다, 호주 }\end{array}$ & $\begin{array}{l}\text { 네덜란드, 뉴질랜드, 덴마크, } \\
\text { 룩셈부르크, 스웨덴, 스위스, } \\
\text { 오스트리아, 프랑스, 핀란드 }\end{array}$ & $\begin{array}{c}\text { 그리스(액션플랜), } \\
\text { 스페인(마스터플랜), } \\
\text { 이탈리아(가이드라인), 포르투갈, } \\
\text { 벨기에(영문 정책서 부재) }\end{array}$ \\
\hline
\end{tabular}

출처」이화여자대학교, ODA 백서수립 및 시행체계 사례연구, 2013

영국, 아일랜드, 호주, 노르웨이의 경우에는 백서수립 배경 및 목표가 자국 ODA 정책의 프 레임워크를 수립하고, 원조규모 확대 및 증대되는 원조의 보다 효과적이고 효율적인 운용을 가능하게 할 중장기적인 $\mathrm{ODA}$ 정책틀로서 개발원조 백서를 수립, 발간하고 있다.

한편, 일본, 독일, 캐나다의 경우, 자국의 개발원조 정책과 방향에 대해 자국민의 인지도롤 높이는 것을 백서 수립의 목표로 명시하고 있는 것으로 조사된다. 
〈표 2〉ODA 백서수립 배경 및 목표

\begin{tabular}{|c|c|c|}
\hline 국가 & ODA 백서수립 배경 및 목표 & $\begin{array}{l}\text { 발간 } \\
\text { 시점 }\end{array}$ \\
\hline 영국 & $\begin{array}{l}\text { 1997년 정권교체후, DFID 창설 등을 비롯한 정부 조직개편 및 } \\
\text { 정책개혁이 진행됨에 따라 종합적인 개발협력 정책 수립을 위 } \\
\text { 해 백서 발간 }\end{array}$ & $\begin{array}{l}\text { 1997년 } \\
\text { 2000년 } \\
\text { 2006년 } \\
\text { 2009년 }\end{array}$ \\
\hline 아일랜드 & $\begin{array}{l}\text { MDGs 달성을 위해 2012년까지 GNI 대비 } 0.7 \% \text { 까지 ODA 규 } \\
\text { 모 확대를 공약함에 따라, 자국 ODA의 성과를 점검하고 보다 } \\
\text { 효율적인 이행을 위해 전략을 마련 }\end{array}$ & 2006년 \\
\hline 호주 & $\begin{array}{l}\text { 2010년까지 ODA 규모 확대를 공약함에 따라 증대되는 개발 } \\
\text { 재원의 보다 효과적이고 효율적인 운용을 위해 포괄적인 } \\
\text { ODA 정책 프레임워크를 마련 }\end{array}$ & 2006년 \\
\hline 노르웨이 & $\begin{array}{l}\text { MDGs 달성과 인류의 경제, 사회, 문화, 정치적 권리 증진을 } \\
\text { 위한 자국의 ODA 방향 강화 및 향후 과제 제시 }\end{array}$ & $\begin{array}{l}\text { 2004년 } \\
\text { 2009년 }\end{array}$ \\
\hline 독일 & $\begin{array}{l}\text { 빈곤 퇴치, 정의 실현, 기후 변화 대응, 평화 구축을 위한 자 } \\
\text { 국 ODA의 기여에 대한 국민 의식 제고 }\end{array}$ & $\begin{array}{l}\text { 2008년 } \\
\text { 2013년 }\end{array}$ \\
\hline 캐나다 & $\begin{array}{l}\text { MDGs 달성과 세계화 시대에 걸맞은 자국 국민의 세계 시민 } \\
\text { 의식 강화를 도모 }\end{array}$ & 2005년 \\
\hline 일본 & $\begin{array}{l}\text { 경제 불황 속 } \mathrm{ODA} \text { 에 대한 국내 여론이 악화된 가운데, 제도 } \\
\text { 개혁 단행, 정책 효율성 및 투명성 제고를 통한 인지 제고 개 } \\
\text { 선 노력 차원에서 백서를 수립 }\end{array}$ & $\begin{array}{l}\text { 2001년이후 } \\
\text { 매년 발간 }\end{array}$ \\
\hline
\end{tabular}

출처」이화여자대학교, ODA 백서수립 및 시행체계 사례연구, 2013

\section{II -2. 백서 수립 체계}

우리 정부는 금년 초 ODA 백서 발간을 위해서 국무조정실 주도하에 기획재정부, 외교부, 한국국제협력단(KOICA) 및 수출입은행 $(\mathrm{EDCF})$ 등 ODA 관계기관들로 구성된 「백서발간 $\mathrm{T} / \mathrm{F}\lrcorner$ 를 발족하였다.

발족된 범부처 백서 발간 $\mathrm{T} / \mathrm{F}$ 는 공적개발원조 주관부처 및 시행기관의 담당관을 중심으로 하여 그간 수차례 협의를 갖고 금년 말 발간 예정인 백서 관련 문헌 조사, 목차 수립 및 세부 목차별 집필 등 관련 발간, 집필작업을 진행중에 있다. 
특히, 백서 초안 집필과정에서 기획재정부 및 수출입은행은 유상원조 정책 및 국별·분야별 사업 내용을 사례와 함께 구체적으로 집필 중에 있으며, 외교부 및 한국국제협력단(KOICA)은 무상원조 정책 및 국별·분야별 사업 내용 및 사례를 기술하고, 통합 ODA 정책 및 관련 체계 등 총괄부문은 국무조정실에서 집필중이다.

우선적으로 금년 초 개최된 1차 백서 $\mathrm{T} / \mathrm{F}$ 회의에서는 관계부처간 ODA 백서의 명칭 및 기본 발간 방향에 대해 의견을 교환하고, 선진국 등 여타 공여국들의 백서발간 사례를 참고하여 백 서의 목차 수립 및 세부 내용에 대한 ODA 유무상 원조기관의 수요를 반영하는 것을 중심으로 논의하였다.

이후 개최된 백서 $\mathrm{T} / \mathrm{F}$ 회의에서는 $\mathrm{ODA}$ 백서의 주요 목차 및 세부 목차(안)를 마련하고 작 성된 백서 초안에 대해 기관별 집필 역할을 분담하였으며, 백서 발간에 대한 전반적인 일정 관 리를 조율하였다.

아울러, 정부차원의 백서 집필 본 편집, 감수 및 출판을 위해서 외부 민간 전문가들에게 관 련 연구 용역을 발주하였으며, 전문가들의 감수, 편집작업 과정에서 지속적으로 정부 및 민간 자문단들의 의견을 수렴해 나갈 예정이다.

백서 $\mathrm{T} / \mathrm{F}$ 는 통합 ODA 홍보 $\mathrm{T} / \mathrm{F}$ 의 분과협의체로 통합, 운영되고 있으며, 통합 ODA 홍보 $\mathrm{T} / \mathrm{F}$ 는 ODA 백서 발간과 함께 ODA 통합 홈페이지 개선(http://www.odakorea.go.kr), ODA $\mathrm{BI}$ (Business Identity) 활성화, ODA 홍보행사간 연계, 청소년 교육관련 맞춤형 프로그램 추 진, $\mathrm{ODA}$ 브로셔 제작 등 유무상 ODA 홍보 관련 의제들을 협의하고 있다.

특히, 금년에는 ODA 이해증진제고 전략서 마련을 위한 연구용역과제가 병행되고 있는 만 큼, 국민들에 대한 ODA 이행증진을 위한 목적에서 $\mathrm{ODA}$ 백서 발간이 갖는 의미는 더욱 크다 할 것이다.

아울러, ODA 백서는 일반 국민들이 손쉽게 이해하고 정보를 습득할 수 있도록 국민들의 눈 높이에 맞는 용어와 쉽게 이해할 수 있는 그래픽 등의 디자인 및 편집 수단들을 최대한 활용, 편집함으로써 우리 고유의 ODA 백서로 발간될 수 있도록 할 계획이다.

참고로, 주요 $\mathrm{OECD} \mathrm{DAC} \mathrm{회원국의} \mathrm{백서발간} \mathrm{체계는} \mathrm{아래와} \mathrm{같다.}$ 


\begin{tabular}{|c|c|}
\hline 국가 & 백서발간 체계 \\
\hline 영국 & $\begin{array}{l}\text { 국제개발부(Department for International Development, DFID) 내 백서전담 } \\
\text { 팀(White Paper Team) 주도로 관련 부처, 시민사회, 일반대중과의 토론을 거 } \\
\text { 쳐 수립 }\end{array}$ \\
\hline 일본 & $\begin{array}{l}\text { 외무성 국제협력국내 개발원조정책기획과(Development Assistance Policy } \\
\text { Division)에 } 15 \text { 명 정도의 백서 전담 조직을 구성, 기획과 집필, 출판을 전담 }\end{array}$ \\
\hline $\begin{array}{l}\text { 아일 } \\
\text { 랜드 }\end{array}$ & $\begin{array}{l}\text { 외교무역부(Department of Foreign Affairs and Trade)의 Irish Aid 주도로 } \\
\text { 발간, } 1 \text { 년여에 걸친 대중, 정부 및 파트너와의 공개 자문을 통해 작성 }\end{array}$ \\
\hline 호주 & 호주 개발협력기구(AusAID)가 총괄, 조율하여 백서 작성 \\
\hline 미국 & $\begin{array}{l}\text { 미국원조청(USAID)의 정책계획조정국(Bureau for Policy and Program } \\
\text { Coordination) 주도로 백서 발간 }\end{array}$ \\
\hline 독일 & $\begin{array}{l}\text { 독일 BMZ 주도로 백서 발간, } \\
\mathrm{BMZ} \text { 내 정책기획(예 : Division P1 - Political Analysis and Strategic } \\
\text { Planning)과 정책수립에 관련된 다양한 부서(예 : Division 110-Policy } \\
\text { Issues: Projects of Private Organizations)의 협의를 통해 결정 }\end{array}$ \\
\hline
\end{tabular}

출처」이화여자대학교, ODA 백서 수립 및 시행체계 사례 연구(중간 보고), 2013

\section{II -3. 백서 구성 및 내용}

ODA 백서는 수립배경과 목표에 따라 담겨지는 내용들이 달라진다. OECD DAC 회원국 중 영국, 아일랜드, 호주의 경우, 개발협력 관련 제도 개혁 또는 $\mathrm{ODA}$ 규모 증대 등을 공약함에 따라, 관련 백서 및 정책서에 개발원조 정책 및 전략의 내용을 구체화하고 있다. 반면 독일, 캐나다, 일본은 자국 개발원조 정책과 방향에 대한 자국민의 인지 제고를 백서 및 정책서 수립 의 목표로 명시함으로써, 기존 정책에 대한 소개에 주안점을 두고 있다.

우리의 ODA 백서는 소통하는 ODA 추진 목표 하에 한국 ODA 추진의 당위성을 설명하는 동시에 한국 $\mathrm{ODA}$ 정책을 포함하는 등 우리 국민들의 $\mathrm{ODA}$ 에 대한 이해를 높이고 관심을 제고 해 나가는 방향으로 작성 중에 있다.

범정부 집필 백서 초안상의 주요 내용을 보면, 우선 '한국과 국제개발협력 Chapter'에서는 국제사회에서 상호 의존적인 ODA 특성상 한국의 발전과 개도국의 발전이 상호 의존적으로 연 계됨에 따른 한국 $\mathrm{ODA}$ 활동의 당위성을 서술하는데서 출발한다. 
아울러, 과거 $\mathrm{ODA}$ 수원국이었던 한국이 현재는 공여국으로 전환된 달라진 위상을 소개하 고, 과거 원조 수원국으로서의 역사(긴급구호, 본격원조, 차관전환기)를 거쳐, 1960-70년대 초청연수 및 전문가 파견사업을 시발로 하여 1987년 대외경제협력기금(EDCF) 창설, 1991년 한국국제협력단(KOICA)이 설립됨으로써 이루어진 한국의 원조활동 조직화를 설명한다.

이와 함께, 2010년 국제개발협력기본법 제정, OECD DAC 가입 및 2011년 G20 및 부산원조 총회(HLF-4) 개최와 함께 한국형 ODA 모델 마련, 2012년 OECD DAC 동료평가(peer-review) 수검 등 발전하고 있는 한국 ODA 역사를 개관한다.

이를 통해 한국이 원조를 받던 나라에서 주는 나라로 탈바꿈한 과정을 소개하고, 수원국의 경험을 바탕으로 하여 향후 개발협력분야의 기여 의지를 기술하고자 한다.

'한국 ODA의 정책 및 전략' 제하 Chapter에서는 구체적으로 한국의 선택과 집중 추진원칙 에 근거하여 26개 중점 협력대상국을 중심으로 하는 국가별 지원전략(Country Partnership Strategy, CPS) 수립 및 이를 통한 분야별 지원 전략과 함께 기후변화, 환경, 양성평등 등 범 분야 이슈들에 대한 한국의 지원 전략 및 현황에 대해 살펴보고자 한다. 또한, 원조 소외국 및 취약국에 대한 지원전략에 대한 평가와 함께 취약국에 대한 국제사회의 논의에 부응하는 우리 의 정책 흐름에 대해서도 기술하고자 한다.

한국은 단기간에 정치·경제사회 등 제반 분야에서 성공적으로 발전한 경험을 갖고 있는 국가 이다. 한국의 특수한 발전경험 및 과정에서의 비교우위, ODA 수행역량, 새마을 운동 등 농촌발 전모델 등은 시간적, 공간적, 사회문화적으로 여건이 다른 국가에 전수해 나갈 필요가 있다.

이와 함께, 보다 나은 $\mathrm{ODA}$ 를 위한 정부의 노력은 다양한 개발주체들과의 파트너십 마련을 통해 구현된다. 수원국의 '주인의식(ownership)'을 고양하고, 원조의 효과성 제고를 위한 수원 국의 국가개발전략을 고려한 중점협력분야를 설정하여 이를 통한 수원국과의 파트너십을 강화 해 나가는 것이 무엇보다 중요하다. 아울러, 다양한 원조공여국 및 국제기구와의 파트너십 강 화를 통해 원조 조화성(harmonization)을 모색해 나가는 것 역시 원조 효과성 제고 측면에서 중요하다 할 것이다.

또한, 우리 정부의 그간 해외 주요 공여국 및 국제기구와의 협력 현황에 대해 기술하고, 신 흥 원조공여국으로서 선진 공여국 및 국제기구의 축적된 노하우를 학습하고 공동사업 또는 평 
가 추진을 통한 우리의 원조 역량강화를 도모해 나가고 있음을 기술하고자 한다.

시민사회 등 ODA에 참여하는 다양한 민간부문의 역할이 증대되고 정부와 민간부문과의 협 력기여의 확대를 위한 촉매제(catalyst)로서의 ODA 역할이 중요한 만큼, 민관 파트너십 (Private-Public Partnership, PPP)의 국내외 논의 동향을 고찰하고, 민관협력 확대를 위한 중기전략, 기업의 ODA 참여를 위한 글로벌 사회공헌활동(Corporate Social Responsibility, $\mathrm{CSR}$ ) 사업에 대한 지원 및 기업의 ODA 참여 유도화 등의 논의 전개에 주목해 나가면서, 민간 부문 활성화 지원을 위한 지원 방향에 대해서도 생각해 보아야 할 것이다.

아울러, 백서에서는 기존 원조 공여국들 사이에서 노정되고 있는 '원조 피로(aid fatigue)' 와 관련 원조효과성에 대한 파리 선언, 아크라(Accra) 행동 계획 및 부산 선언 등에 대한 논의 동향을 점검하고, 원조 효과성 제고를 위한 우리의 노력을 설명하여야 할 것이다.

특히, 개발협력사업의 효과성, 특히「원조를 넘어선 개발」을 위한 국제협력사업은 국내 및 국 제사회에서 모두 주요한 이슈인 만큼, 이를 통해 우리 ODA 발전방향을 제시해야 할 것이다.

2012년 한국은 OECD DAC로부터 가입이후 처음으로 '동료평가(peer review)'를 받았는데, 한국의 개발협력 정책과 집행 개선을 위한 권고사항을 담은 평가였다.

특히, 동 평가 권고사항의 이행 방안을 위한 협의를 통해 ODA 생태계를 구성하는 사

회 전반의 협력과 역량 강화가 필요한 부문도 백서에 기술되어야 할 것이다.

마지막으로, $\mathrm{ODA}$ 백서를 통해 국민과의 소통이 보다 원활해지고 $\mathrm{ODA}$ 관계자들이 우리 $\mathrm{ODA}$ 에 대한 공동의 비전을 공유해 나가는 동시에 $\mathrm{ODA}$ 에 대한 더 많은 관심과 지원이 이어질 수 있기를 기대해본다.

\section{III. 결론}

“어떠한 목적을 달성하기 위해 백서를 발간하는가?”라는 질문을 받는다면 $\mathrm{ODA}$ 정책에 대 
해 대내외적으로 공개하고, 국민들의 ODA에 대한 이해도 제고를 통해 ODA 양적 확대 및 질 적 개선을 위한 정책적 토대를 구축하고자하는 정부의 노력을 구체화하기 위함이라고 답할 수 있을 것이다.

우리 정부는 $\mathrm{ODA}$ 지속 확대 및 모범적·통합적 개발협력 추진』을 통해 수원국의 자립역량이 배양되도록 지원해 나가는 동시에, 국제사회에 모범이 되는 개발협력을 추진하기 위한 노력을 앞으로도 계속해 나갈 것이다.

한국 $\mathrm{ODA}$ 의 양적 확대 및 질적 개선을 위해서는 국민의 세금으로 이루어지는 공적개발원조 에 대한 국민들의 관심과 지지에서 출발하여야 함은 자명하다. 이러한 측면에서 금년 말 예정 된 $\mathrm{ODA}$ 백서 발간의 의미를 다시 한 번 생각해 볼 수 있을 것이다. 


\section{참고문헌}

이화여자대학교, 2013, ODA 백서수립 및 시행체계 사례연구 (중간보고서)

한국국제협력단, 2013 , 국제개발협력의 이해

KOICA ODA 교육원, 2013, 국제개발협력 첫걸음

국무조정실, 2013 박근혜정부의 국정과제 보도자료

국무조정실, 2013 업무보고 보도자료

외교부, 2013, 국민행복, 희망의 새 시대를 여는 신뢰외교, 2013 외교부 업무보고 보도자료 OECD, 2012, DAC Statistical Reporting Directives

OECD, 2012 DAC Peer Review on the Republic of Korea 